\title{
Receptor-Type Tyrosine-Protein Phosphatase Eta
}

National Cancer Institute

\section{Source}

National Cancer Institute. Receptor-Type Tyrosine-Protein Phosphatase Eta. NCI

Thesaurus. Code C37313.

Receptor-type tyrosine-protein phosphatase eta (1337 aa, $\sim 146 \mathrm{kDa}$ ) is encoded by the human PTPRJ gene. This protein plays a role in protein dephosphorylation, chemotaxis and the negative regulation of receptor-mediated signaling, cell proliferation and cell growth. 